\title{
The Applied Analysis of Speech Act Theory in College English Teaching
}

\author{
Yan Zhang \\ School of Foreign Languages, Jilin Agricultural University, Changchun 130118, China
}

Keywords: college English; speech act theory; applied analysis.

\begin{abstract}
The locutionary act is a speaking activity, which is a vocal behavior, and its contents can be sentences, phrases, words and so on to express a certain concept or meaning. The illocutionary act is an act carried out by speaking, which involves the speaker' intention, such as assertion, doubt, order, description, explanation, apology, thanks and so on. The perlocutionary act is the effect of words for the listener, such as making someone angry or successfully persuading someone to do something. The following illustrates how these three different speech acts are organically linked through a concrete example: Suppose John was preparing to go out at night in cold weather; the mother said to him, "John, it's very cold outside." "the sentence itself that mother said (according to the requirements of English, the sound compose word, the word compose the sentence, and say with the correct tone) is locutionary act; the intention that mother said this sentence was to ask John to wore coat and then went out, this is illocutionary act; John heard the words of the mother, wore a coat and then go out, and that is perlocutionary act. It can be seen from the description of this above example that the locutionary act analyzes the literal meaning expressed by the speakers' words, this is literal meaning, the illocutionary act analyzes the implicit true meaning of the speaker's through literal meaning, that is implication, perlocutionary act analyze that the speaker' intention are understood by the listener and produce the effect, that is perlocutionary effect.
\end{abstract}

\section{Brief Introduction of Speech Act Theory}

Speech act theory has been comparatively perfect after years of development; this concept has been widely used in many aspects of social life, and plays a huge role. Speech acts mainly include perlocutionary act, illocutionary act, locutionary act, which is the three themes of speech acts, illocutionary act have a key core role. At present, the College English teaching is relatively weak in speech act aspect, College English teaching still continues the teaching method of high school, and that is focusing on the learning and mastering of basic knowledge of English, important points is still words, grammar learning and article comprehension, but English as language teaching projects, learners are needed to apply it into to their daily lives directly, and further deepen their understanding and master for English knowledge in the actual application process.

In order to guide students to effectively study and establish a foundation for English courses, the importance and the key of speech act theory must be fully understood. By applying the speech act theory to college English teaching, it can make students realize the speech nature of language, then guide the students to develop scientific learning methods and contents in the daily learning process for their own learning situation, appropriately strengthen the learning content and training content of language expression, ultimately considerably improve their own language expression skills, and it is the only way to learn language, it have a key role for using English communicate with others effectively. One of the ultimate goals of English learning is to help learners to complete communication with others in English, and achieve the desired communication purpose.

Speech act theory belongs to the category of psychology, and speech act theory is an important theory in the pragmatic study of language. It was originated with the British philosopher John Austin in the late 50's of the 20th century. According to speech act theory, we are performing actions when we are speaking. According to speech act theory, a speaker might be performing three acts simultaneously when speaking: locutionary act (the act of uttering words, phrases, and clauses), illocutionary act (the act of expressing the speaker's intention) and perlocutionary act (the act performed by or resulting from saying something). 
John Searle, an American philosophical linguist, has an in-depth discussion for speech act; consult the appropriate conditions for implementing illocutionary act: preparatory condition, sincerity condition, propositional content condition and essential condition, classify speech act of indirect instructions. The various ways to implement indirect is "instruction", consider from several factors this behavior involved, the speaker (instructor), the listener (command object), and the action that the speaker wants to listener to do. For example, please ask someone to pass salt bottles at the table; there can be the following indirect forms:

The speaker as starting point:

a) State wish: I would like you to pass me the salt.

b) Ask wish: Would I like you to pass me the salt?

The Listener as starting point:

1a) Presentation ability: You can pass me the salt.

1b) Inquiry ability: Can you pass me the salt?

2a) Statement will: You want to pass me the salt.

2b) Ask will: Would you mind passing me the salt?

3a) State future action: You will pass me the salt.

3b) Ask the future action: Will you pass me the salt?

The action as starting point:

a) State reason: The soup is not salty enough.

b) Ask reason: Wouldn't it be a good idea if we add some salt to the soup?

He divides illocutionary act into five categories, each kind of behavior has a common, general purpose.

The five categories are:

Statement category: state or describe the truth that speaker thinks;

Instruction category: try to make the listener to do something;

Commitment category: the speaker promise to have some behavior in the future.

Expression category: express feelings and attitudes to one status.

Declaration category: through talk cause change.

The behavior in each category has the same purpose, but illocutionary act with the same purpose may have a different degree of illocutionary force.

Some scholars, such as Sperber and Wilson (1986), have different views on the speech act theory: they thought that the speech act theory does not have necessity of existence at all, therefore, Levinson' (1983) View, both "speech act is the same to premise and meaning, which is the main phenomenon that any common pragmatic theory must explain", raised the question and pointed out that "speech act theorists are concerned about the large number of phenomena, which is no special interest for pragmatics "

In the early 1990s, after Thomas (, 1995) analyzed Austen's speech act theory in detail, the theory had a great influence on linguistics circle, which are mainly in the following four reasons:

A. when truth-conditional semantics have setbacks, the introduction of "How to Do Things with Words" book is very timely;

B. his views are clear and easy to understand;

C. Although he has changed his viewpoint before and after, but his work has always maintained a coherent ideological line;

D. Many questions that he proposed are still an important subject of pragmatics research.

There are some problems in speech act theory as well, which is reflected in the following three aspects:

Performative hypothesis

Speech act can not only narrate things, point out things, but also act, pass pragmatic force or performative force. However performative forces are explicit or implicit in the words are explicit or implicit; the point that performativ force is always expressed by performative can be hypothesis (Sadock, 1988). 
It can be seen that the scholars who hold this hypothesis thought that the performative sentence included or implied performative verb, the subject is the first-person singular. However, only the performative verb hypothesis has the following three aspects of shortages:

A. The form and grammar means that can distinguish performative verb from other verbs exist;

B. The appearance of performative verb does not necessarily guarantee the implementation of an act, such as ritual performatives and collaborative performatives, it is restricted by the necessary and proper conditions, otherwise it cannot act in words, meta-language performatives will produce similar problems;

C. Can act in words without performative verb.

This hypothesis is directly challenged by indirect speech acts. This laid the foundation for the indirect speech act theory of Searle later.

Social culture

The speech act theory can explain many language phenomena that syntax and truth-condition semantics are incapable of action. It can be seen that the contribution of speech act theory is undeniable, but any theory is incomplete.

Austin and Searle both adhere to the conventionality or habit of speech act to a certain extent, but Searle also stressed the intentionality. He thought that courtesy is the most important motive for the use of indirect speech acts (such as "requests"), but he ignores the social and cultural characteristics that affect the polite degree of speech act.

Koyama (1997) criticized this point and thought that the notions of "speaker" and "listener" of speech act basis also have cultural feature, so that speaker and listener with different cultural backgrounds will express different features in human interaction and language use.

Rosaldo (1982) thought that speech act theory ignores the restrictive effects of important situational and cultural factors on language use. Knowing how to speak is equal to how to act in words and when act in words. According to this, he opposed that Searle's divided speech acts into: assertives, directives, commissives, expressives, declarations, etc.), because such a classification is not basis of cross-cultural typology in the language use.

At the same time, after analyzing other corpus except English, Wierzbicka (1985) points out that speech acts such as promises, orders, and warnings are implemented in a conventional way in English, and it has a cultural dependence in some languages, therefore, the cultural particularity of speech acts should be emphasized.

Constraints

When commenting on speech act, Mey (1993) also thought that speech behavior should be combined with the societal contexts of people. And then he proposed "pragmatic act" concept from the perspective of society and language.

The speech act should involve certain social constraints from a social point of view, such as the special education, age, gender, occupation received by the speaker, etc. These constraints form part of the background information of people in communication.

From a viewpoint of linguistics, Mey is concerned about the language form that can be used to implement a pragmatic act, and what language and language form are used for implementing pragmatic act.

It seemed to Verschuern (1999) that it is language adaptability problem. Speech act is part of pragmatic act, and its understanding needs to rely on contextual conditions and communicative purposes. Thus pragmatic act is restricted by contextual constraints, which is adaptabilityact. The context includes social customs, culture, social structure, or proper conditions.

Mey thought that the previous speech act theory cannot explain the social basis of speech act under this support of viewpoint. 


\section{Speech Act Theory is Brought into College English Teaching}

Teacher-student relationship is the most important interpersonal relationship in the school, and teacher-student interaction is the most important form of social interaction in school. How teachers and students interact, which directly affect the success or failure of education and teaching, and affect the realization of school functions. "Reform Program for Basic Curriculums," pointed out that "the teaching process is the teacher-student interaction and common development process." It can be seen from the classroom teaching observation practice, teachers' teaching speech act affect the teacher-student interaction, poor teaching language of teacher obstruct the students' subjectivity, and affect the development of teacher-student relationship.

The requirements of speech act, including the comprehensibility of expression, the authenticity of the statement, the sincerity of the speech subject and the correctness of the behavioral composition, the validity of the result produced. Promote the development of students' language; construct active and effective teacher-student interaction.

The speech act theory is brought into English, when the speaker said these words, it is not to make statements or description, but complete a certain action. For example: marriage, naming, bequest, betting. Of course, these four examples are speeches which are used in some customary activities, but condition by speaking to do something is not limited to these customary activities. For instance, "I promise....", "I warm...", "I apologize....", "I welcome...." and so on. When saying these words, the speakers implement "promise", "warning", "apology", "welcome" and other actions, respectively,.

Although the sentence which has act does not have true and false, but it needs to meet certain conditions, which are appropriate or possible. At the launching ceremony of the new vessel, only the designated person has the right to name the new ship, this person must speak in accordance with the relevant procedure. For example, the person who gives a watch must have a watch; for those who bet for the rain, if the next day is raining, six pence must be paid for those who bet on it.

Shi Ou had deeply studied the teaching language in "teaching doctrine". The teaching process is the flow process of language, teaching content is the content that language composes. Teaching is carried out around the lecture, explanation, discussion, questioning, answering, reading, writing, listening and so on. Language is the necessary intermediary for teaching to be implemented, which is the most basic means of teaching and the most important tool. The basic pattern of teaching language is summarized: question and answer mode, narrative mode, causative order, teaching mode, interpretive language mode.

Austen thought that the locutionary act can sometimes, simultaneously or itself is illocutionary act in speech act theory. This condition usually happens when the speaker is directly showing his intentions. This expression is also known as direct expression, in English, for instance, order are used to express "command", the suggest are used to express "recommendations" and so on. Direct expression also includes directly express their own intentions in accordance with the use of sentences type of semantic categories, for example, the declarative sentence are used to express "statements", the interrogative sentence are used to express "inquiry", the imperative sentence are used to express "order" and so on.

However, the locutionary act and illocutionary act are sometimes different in speech acts. This is indirect expression that people say. Indirect expression mainly includes two aspects: First, action verbs are not directly used to express the speakers' intention, but use other means to express apology, order, advice and so on. For example, do not use "I order you to go out," but use "You are not welcome here." Second, a sentence type is used to express meaning usually belong to what another sentence type express, for example, the question is not express "ask", but is "request", "invitation" and so on. For example:

(1) Could you tell me where the nearest post office is?

(2) Would you come to join us at the party?

In a speech act, whether locutionary act and illocutionary act are equal, and it is often depended on the context. In other words, whether the speaker's meaning is expressed in a direct or indirect way in 
the speech communication or not, and the listener needs to judge it in accordance with the specific context.

Speech act theory can also be applied directly to oral teaching, the first is the teacher's classroom English teaching, in order to ensure that college students can fully understand the expression meaning of the teachers, the teacher generally choose to use both English and Chinese, so that it can help students master meaning of a word, phrase and sentence in a short time. On the other hand, due to the large differences exist in the English foundation of college students, in order to meet the learning needs of most students in the class, the teacher can promote the communication between teachers and students through reasonable application of speech theory, and help students to master the teacher's intention quickly. In addition, the basis of classroom teaching can be carried out is the effective communication between teachers and students, if teachers cannot fully take care of students' English foundation, it will cause classroom difficult to achieve the desired teaching effect, but also combat hurt students' learning enthusiasm to a certain extent, and ultimately it is not conducive to students' English learning progress.

The speech act theory can also be applied in various teaching activities, the most common form of classroom activities is a role-playing in college English classroom, this activity can greatly stimulate the students' learning enthusiasm, by guiding students to play a specific role, it contributes to promote students actually into the specific context, so as to deeply understand the language and ideas of people, this process can help students deeply understand and master the connotation of English. The corresponding evaluation links should be established in this process, and actively establish an effective interaction mode.

Oral teaching can not only strengthen the English language communication ability of college students, but also can promote the students' comprehensive quality development. With the progressing steps of world economic integration, the societal demand for talent will be diverse in social development in the future, and only comprehensive talents who comprehensively develop will be better adapted to the development of future society. College English teaching does not only help college students to learn English, but also can exercise students' autonomous learning ability and deep understanding of the connotation of Chinese and Western culture, and it help college students occupy a certain advantage in the following work process.

\section{Conclusion}

The mainstream tendencies of Teachers' classroom speech act are: basically clear sentence, flat intonation, fluent language, kind expression, generous behavior, concise and decent gestures, simple and clear board writing, clear and organized writing.

Classroom teaching speech is directly related to the teaching quality and associates with the national cultural quality, which must be given enough attention. It is suggested that the teacher should not only recite the textbook, prepare the teaching method, but also prepare the classroom speech, consciously gradually improve the level of classroom speech, the school can organize teachers to carry out specialized classroom speech skill training, such as oral skill training, body language skills training, blackboard writing skill training, and it helps teachers improve the level of classroom speech and improve teaching quality.

\section{References}

[1]. Huang Gang. The innovative applications of speech act theory in college English teaching [J]. Journal of Heilongjiang College of Education, 2016, 35 (10): 128-130.

[2]. Liu Xiangya. The application research of indirect speech act theory in college English listening teaching [J], Journal of Jiamusi Vocational Institute, 2016 (5).

[3]. Zhang Yining. Simple Analysis on new direction of college English teaching under the guidance of indirect speech act theory [J]. Asia-pacific Education, 2015 (4): 106-107. 